\title{
When Eating "Correctly" is not so Healthy: Factor Analysis of the ORTO-15 in University Students from Mexico City
}

Tena $\mathrm{A}^{1 *}$, Parra $\mathrm{A}^{2}$, Barajas $\mathrm{M}^{3}$, Bilbao $\mathrm{GM}^{2}$, Diaz MC $^{1}$, Flores $\mathbf{I}^{2}$, Ruiz $\mathrm{A}^{\mathbf{1}}$

${ }^{1}$ Department of Psychology, University of Ibeoamerican, Mexico

${ }^{2}$ Department of Health, University of Ibeoamerican, Mexico

${ }^{3}$ National Autonomous University of Mexico, Complexity Science Center, Mexico

*Correspondling author: Antonio Tena Suck, Department of Psychology, University of Ibeoamerican, Mexico

Received: December 22, 2020; Accepted: J anuary 26, 2021; Published: February 02, 2021

\begin{abstract}
Background: The objective of this study was to analyze the psychometric properties of the ORTO-15 questionnaire, in Mexican university students. This questionnaire was designed to assess the presence of Orthorexia Nervosa (ON).
\end{abstract}

Method: The sample consisted of 911 Mexican university students $(65.4 \%$ women) aged between 18 and 28 years $(M=21 \pm 1.9)$ who answered the Spanish version of the ORTO-15.

Results: The results of the factor analysis with a varimax rotation yielded a structure of 14 test items made up of four factors, which explained $52.4 \%$ of the variance. Likewise, an adequate internal consistency was obtained (Cronbach's alpha=0.78).

Conclusion: The psychometric properties of the Spanish version of the ORTO-15 are supported as a reliable tool for the evaluation of orthorexia nervosa in the Mexican population; however, it is important to consider the influence of the Mexican culture. Its use is expected to contribute significantly to a better understanding of the impact these behaviors have on Mexican population.

Keywords: ORTO-15; Orthorexia Nervosa; Eating Disorders; Mexican Population; University Students

\section{Introduction and Background}

Being overweight and obese are considered major public health problems in Mexico, representing a combined prevalence of 36\% in the adolescent population and $72.5 \%$ in adults 20 years of age or older, according to the Halfway Health and Nutrition National Survey 2016 (Midway National Health and Nutrition Survey, 2016), carried out by the National Institute of Public Health (ENSANUT-MC). This is the reason why the primary strategies of many public health policies have been directed at promoting a healthy diet, to reduce the negative health consequences relating to obesity [1]. However, along with the increase in overweight and obesity, there has been an increase in the prevalence of Eating Disorders (ED) and Risky Eating Behaviors (REB), which can be represented in the rise of eating disorders in adolescents of $1.3 \%$. This is a number higher by half of the percentage obtained by the ENSANUT in 2006 [2].

There is a thin line between wanting to eat healthily and have a pathological concern for eating healthily [3]. In some cases, the selfimposition of eating rules to improve one's health can be harmful. This search for the "perfect healthy diet" becomes an exaggerated and pathological concern, a condition currently known as Orthorexia Nervosa (ON) [4].

The word orthorexia is a neologism from the Greek Orthos (correct) and Orexia (appetite, nutrition), which alludes to the atypical need to "eat properly". It constitutes a new eating disorder, which main symptom is an obsessive and pathological approach to eating foods that are perceived as healthy [5]. Likewise, physician Steven Bratman coined the term Orthorexia Nervosa (ON) in 1997 and defined it as "having a pathological obsession for eating a healthy diet" [4]. In recent years, many articles that refer to orthorexia have been published; however, currently there is still no universally accepted definition of orthorexia. A short literature review of current articles on the topic of orthorexia revealed the following themes:

A pathological obsession with correct nutrition characterized by a restrictive diet, a ritualized and rigid eating pattern, avoiding the consumption of certain foods that are considered impure or unhealthy $[3,6,7]$. A fixation with consuming healthy food [8-11]. An excessive concern with eating healthy food [12-15]. An obsession with the consumption of healthy foods, which can lead to restrictive diets, sometimes with a deficiency of essential nutrients and a modification of social relationships [16].

ON is defined using different terms such as obsession, fixation, and concern, which are further emphasized with terms such as excessive or pathological. Food is classified by the individual based on quality levels (as healthy or as unhealthy or impure), while the diet is described as restrictive or rigid, with behavioral aspects such as modifications in social relationships [5]. Despite the increase in interest over ON, the concept remains controversial. Therefore, it is not yet recognized as a disorder by the DSM-5 (Diagnostic and Statistical Manual of Mental Disorders) or by the International Classification of Disease (ICD-11). This is the reason why, just as there is no consensus in its definition, neither is there any diagnostic
Austin J Nutr Metab - Volume 8 Issue 1 - 2021

Submit your Manuscript | www.austinpublishinggroup.com

Tena et al. (C) All rights are reserved
Citation: Tena A, Parra A, Barajas M, Bilbao GM, Diaz MC, Flores I, et al. When Eating "Correctly" is not so Healthy: Factor Analysis of the ORTO-15 in University Students from Mexico City. Austin J Nutr Metab. 2021; 8(1): 1100. 
criteria and evaluation instruments as potent as those which measure $\mathrm{ED}$, but for ON $[6,17]$. However, there are attempts to establish the diagnostic criteria of ON by various researchers [18-21]. Established that two main characteristics must be present for $\mathrm{ON}$ to be diagnosed [5]. Primarily, an obsessive approach in eating practices, which aim to promote an optimal well-being through healthy eating. Examples include inflexible diets, persistent and recurrent worry with food, and compulsive behavior. Secondarily, significant clinical deterioration, represented in medical or psychological complications, great anguish and/or deterioration in important areas of functioning [5]. Among the characteristics that have been observed in patients with ON, they present similar features than individuals with eating disorders, and obsessive-compulsive disorder [17]. Specifically, the similarities with anorexia nervosa have led to a debate over whether $\mathrm{ON}$ is a unique disorder, a subtype of AN or an Obsessive-Compulsive Disorder (OCD) $[5,6,17,22]$.

Some of the similarities between ON and Anorexia Nervosa (AN) include perfectionism, high levels of anxiety, a need to exercise control, viewing adhering to a healthy diet as a marker of selfdiscipline, limited vision of their condition, and a denial of functional impairments associated with the disorder. The similarities between ON and OCD include recurrent and intrusive thoughts about food and health, an exaggerated concern around pollution and impurity, and a great need to organize food and eat in a ritualized way, as well as having limited time for other activities, since the adherence to a strict eating style interferes with normal routines $[5,6,17,22]$. However, despite the similarities, ON presents significant differences with these disorders. As for AN, the main difference is the motivation to eat in a disorderly manner. Given that, while individuals with AN alter their eating patterns to lose weight due to their concern with body image and fear of gaining weight, individuals with ON alter their eating patterns in order to improve their health, without the fear of gaining weight. $\mathrm{ON}$ is focused on the quality of the food and not on the quantity. Likewise, while individuals with AN tend to hide their behavior, individuals with $\mathrm{ON}$ are more likely to exhibit their habits. Finally, regarding OCD, the most significant difference is that the content of the obsessions in $\mathrm{ON}$ is perceived as ego-syntonic instead of ego-dystonic $[5,6,17,22]$.

There is also no consensus on which evaluation instrument professionals should use to measure the psychometric characteristics of $\mathrm{ON}$, which is problematic because an evaluation instrument is an indispensable part of research; it is crucial to have valid and reliable instruments for its assessment. So far the instruments that have been developed with this objective in mind are the Bratman Test (BOT) without validation studies; the ORTO-15 test, the Eating Habits Questionnaire (EHQ) [17] and the Dusseldorf Ortorexia Scale (DOS) [5].

However, so far, the ORTO-15 is the most widely used instrument in studies related to ON. In a way, it has been considered the golden standard in the evaluation of $\mathrm{ON}$, regardless of its psychometric properties [3,9,17,23-25].

The ORTO-15 [26] was developed based on the test proposed by Bratman Test (BOT) and the Minnesota Multiphasic Personality Inventory (MMPI). It is made up of 15 questions in a four-point answer format ranging from "always" to "never." The questions address three dimensions that are: a) rational cognitive area (questions: 1,5 , 6, 11, 12 and 14), b) clinical area (questions: 3, 7, 8, 9 and 15) and c) emotional area (questions: 2, 4, 10 and 13). The total scale score ranges from 15 to 60 points, where lower scores are indicative of $\mathrm{ON}$, while higher scores indicate a normal eating pattern. Some authors have used a cut-score below 35 points $[24,27,28]$, but a score below 40 has shown a better predictive capacity [26]. On the other hand, the English version has also been used for validation in other languages $[3,23,29]$. The ORTO- 15 has been translated and validated in several languages: Turkish, Portuguese, Hungarian, Polish, German, and Spanish $[5,17,30]$. On the other hand, studies have been conducted to analyze the internal structure of the instrument with different results among them, showing inconsistencies with respect to the validity and internal reliability $[3,17]$.

For example, Arusoglu and collaborators (2008) applied the ORTO-15 in a sample composed of 994 university students, obtaining a weak internal consistency with a Chronbach's Alpha equal to 0.62 , which derived in the elimination of various items from the original questionnaire and ended up with a final unidimensional version made up of 11 elements. On the other hand, Varga and collaborators (2014) tested this instrument in 819 Hungarian university students, resulting in the elimination of 4 items and an acceptable internal consistency (Chronbach's Alpha=0.82). In the same sense, the ORTO-15 was used in a sample of 1029 German individuals, with a unidimensional version of the scale as a result, made up of 9 elements and a moderate consistency equal to 0.67 . Also, [29], obtained a version conformed by 9 items in a sample of 400 students, with a Chronbach's Alpha equal to 0.64 . In general, all the translated versions of the ORTO15 have eliminated one or more questions to increase the validity and internal reliability of the original questionnaire, which has led to shortened versions ranging from 9 to 14 items [17,31]. Regarding this structure and item quantity variety, various authors consider that this variation has its origin in sociocultural differences, as well as the diverse customs regarding food [32]. Given that the relative data of the epidemiology for any disease is determined by the sensitivity and specificity of the evaluation instruments, it has been difficult to obtain reliable estimates of the prevalence of $\mathrm{ON}$, since, as mentioned above; there is still no consensus on the evaluation instrument to use [6]. The objective of this study was to validate and obtain the reliability of the Orthorexia Nervosa Questionnaire (ORTO-15) in Mexican university students. Parra-Fernandez and her collaborators (2018) previously validated this instrument in Spanish. It consists of 15 questions on a Likert scale with 4 answer options that are: "always, often, sometimes, never". A score of 40 points or less means that there is a presence of a pathological behavior characterized by a strong concern for healthy eating; however, the score does not imply having a mental health disorder. Finally, the test items assess the obsessive attitude of people to choose, buy, prepare, and consume food that they consider healthy. A cut-point of less than 35 has been shown to increase specificity and improve diagnostic trends [24,26]. In this study, ON refers to the phenomenon of obsessive and sensitive behavior towards health and nutrition [27].

\section{Methods}

\section{Participants}

911 university students participated in the study (65.4\% women 
Table 1: Matrix of factors extracted by varimax rotation and factor loads obtained.

Factor 1 Obsessive Cognition

Test Item

7. Does the thought about food worry you for more than three hours a day?

Factor load

3. In the last 3 months, did the thought of food worry you?

0.76

4. Are your eating choices conditioned by your worry about your health status?

Factor 2 Rational Cognition

Test Item

12. Do you think that consuming healthy food may improve your appearance?

6. Are you willing to spend more money to have healthier food?

11. Do you think that eating healthy food changes your lifestyle (frequency of eating out, friends ...)?

10. Do you think that the conviction to eat only healthy food increases self-esteem?

14. Do you think that on the market there is also unhealthy food?

Factor 3 Emotional Regulation

Test Item

2. When you go in a food shop do you feel confused?

1. When eating, do you pay attention to the calories of the food?

13. Do you feel guilty when transgressing?

Factor 4 Normative Social

Test Item

15. At present, are you alone when having meals?

8. Do you allow yourself any eating transgressions?

9. Do you think your mood affects your eating behavior?

Note: Valid cases $=889, \alpha=0.78$ for the total scale.

and $34.6 \%$ men) with an age range between 18 and 28 years $(\mathrm{M}=21$ and $\mathrm{SD}=1.9$ ), belonging to different undergraduate careers. Out of these, $27.8 \%$ are enrolled in nutrition degrees, $20.5 \%$ in social sciences, $16.9 \%$ in arts and humanities, $15.6 \%$ in engineering, $9.9 \%$ in economic-administrative careers, and $9.4 \%$ in health sciences.

\section{Instrument}

ORTO-15 questionnaire: The ORTO-15 questionnaire was originally developed in Italy by [27]; in its original form, it consists of three factors that measure thoughts, emotions and behaviors related to food. The ORTO-15 consists of 15 test items in the Likert format, which objective is to examine the obsessive behavior of a person with respect to the selection of foods, their preparation and consumption habits, as well as attitudes towards food considered "healthy". Test items are included such as: "Whenever you eat something, do you check how many calories does it contain? Would you be willing to spend more for a healthy diet?" In this questionnaire the value of 1 is assigned to the answer that is more indicative of orthorexia and 4 to the response that indicates a normal feeding behavior, diagnosing those individuals with a score lower than 40 with orthorexia for the general population.

\section{Procedure}

A non-experimental cross-sectional investigation was carried out to analyze the psychometric properties of the ORTO-15 questionnaire in Mexican university students. Prior to the application, a process of validation by judges was conducted (with the help of experts in the topic) to verify that the translation into Spanish was understandable and measured the orthorexia variable appropriately. Once this version was reviewed, it was applied in a group after receiving prior consent from the subjects. The University's Ethics Committee for Research approved the study.

To protect the confidentiality of the participants, they were informed that their answers would be treated anonymously, confidentially, and for statistical purposes only. Finally, they were asked to choose the answer they considered most appropriate to their attitudes on the subject. For ethical reasons, the participants did not receive any financial compensation in exchange for their participation in the study.

\section{Results}

After having captured the data, an initial analysis of test item's discrimination was carried out, in order to analyze if all of them met the necessary methodological requirements, considering three criteria: a) frequency distribution, $b$ ) differences between the means of extreme groups for each test item and c) correlation between each test item and the total scale. Further on, a Principal Component Analysis with a Varimax rotation was used to identify subjacent dimensions from the ORTO-15 Questionnaire. In the original solution, the eigenvalues superior to 1 showed the existence of four factors, converged in eleven iterations that explained $49.9 \%$ of the total variance. The antiimage matrix was also obtained to observe which test items could be decreasing the total variance explained by the set of test items. As the result of this matrix, the test item number 5 was eliminated: "In your opinion, is the taste of the food the main criterion when 
Table 2: Statistics for the total-element for the total scale.

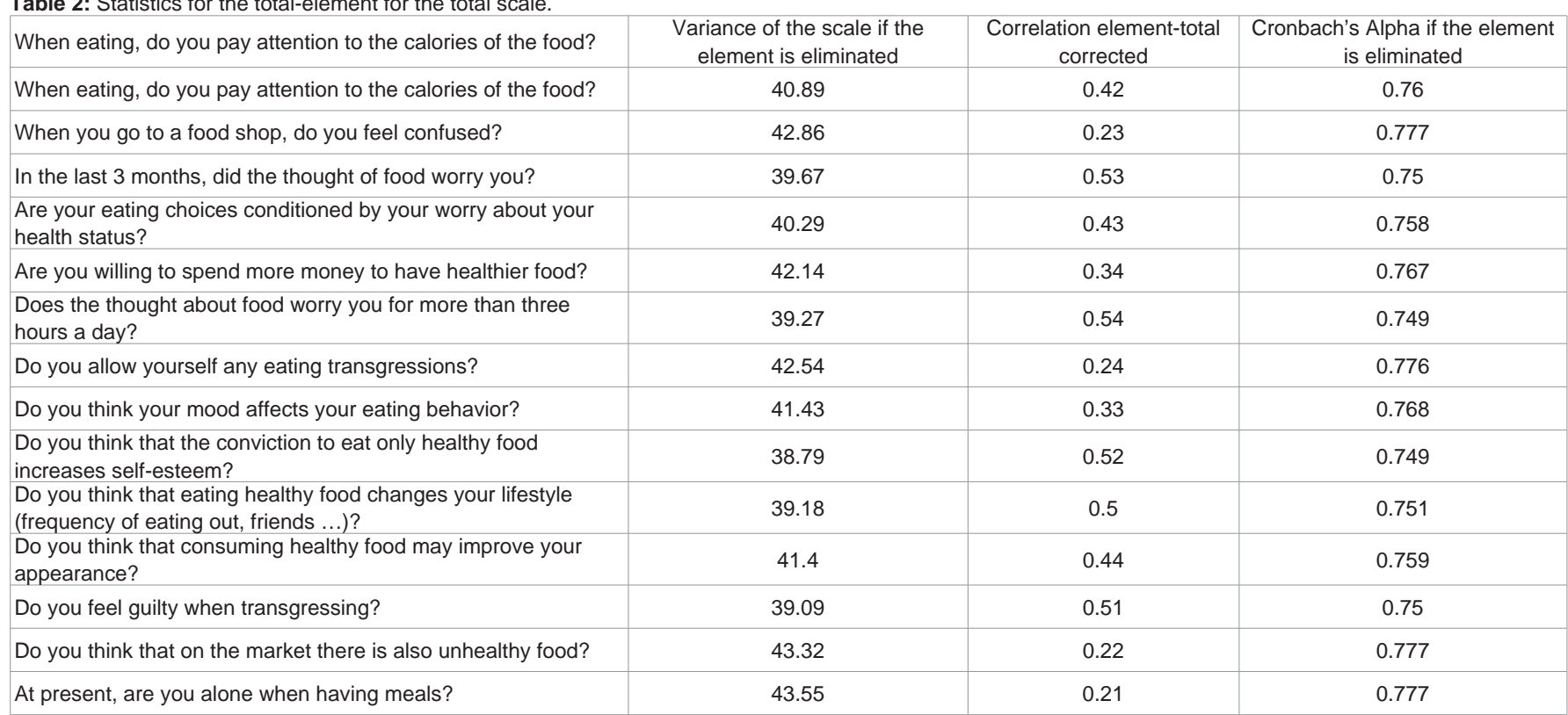

determining its quality?". With said chance, the total variance explained increased from $49.9 \%$ to $52.5 \%$. With the remaining 14 items, the internal consistency of the scale was obtained, measured by Cronbach's Alpha, which resulted in 0.78 ; this is an acceptable value. To investigate if any of the test items was decreasing the total alpha of the scale, the correlation between each item and the total scale was analyzed. Consequently, it was observed that there was no significant change in the alpha if any of the test items were eliminated. Therefore, the decision was made to keep the 14 test items, as shown in (Table 1). On the other hand, the Bartlett's Sphericity test, which evaluates the applicability of the factorial analysis in each of the studied variables and its statistical significance (2329.59, $\mathrm{gl}=105, \mathrm{Sig}<0.001)$. This implies that the Principal Component Analysis is an adequate tool to factorize this specific group of data. Similarly, the Keizer-MeyerOlkin index was applied (0.829) with a positive result. This indicates the existence of an adequate test in relation to the sample's size.

\section{Factor description}

Factor 1, called "Obsessive cognition" corresponds to test items 3,4 and 7 , that refer to thoughts and attitudes that generate excessive worry. Given their duration and intensity, it's difficult to control them on a daily basis, causing an emotional discomfort to stay healthy and eat "correctly." These thoughts are hypervigilant and can be used as a stress coping strategy.

Factor 2 was named "Rational Cognition", and contains test items $6,10,11,12$ and 14 . It is a mental-rational construction that generates logical thoughts in order to evaluate, understand and act to have "healthy lifestyles". It indicates a great need to be accepted for one's appearance, self-confidence, and for the approval of others.

Factor 3, "Emotional Regulation", was composed of test items 1, 2 and 13. It is a factor that measures the influence of emotions on the individual, how he or she experiences and expresses them. In this sense, food has a strong motivational component for the individual in terms of their biological and social adaptation.

Table 3: Correlation between factors.

Table 3: Correlation between factors.
\begin{tabular}{|c|c|c|c|c|}
\hline & Factor 1 & Factor 2 & Factor 3 & Factor 4 \\
\hline Factor 1 & 1 & $0.45^{* *}$ & $0.46^{* *}$ & $0.28^{*+}$ \\
\hline Factor 2 & -- & 1 & $0.30^{*+}$ & $0.30^{*+}$ \\
\hline Factor 3 & -- & -- & 1 & $0.26^{*+}$ \\
\hline Factor 4 & -- & -- & -- & 1 \\
\hline
\end{tabular}

Note: ${ }^{*} p \leq 0.05,{ }^{* *} p \leq 0.01$.

Finally, factor 4 "Normative social", contains test items 8, 9 and 15. It is a factor that measures compliance with the social rules accepted by the group they belong to and that people must follow to have a healthy coexistence with food (Table 2). Finally, a Pearson correlation was run between factors, finding slight but statistically significant relationships, which confirms the internal consistency between the dimensions that make up the scale, as shown in (Table 3).

\section{Discussion}

The objective of this study was to investigate the validation and analysis of the psychometric properties of the ORTO-15 questionnaire for the evaluation of symptoms of orthorexia nervosa in the Mexican population. This work was motivated by the need to have a psychological evaluation tool for university Mexican students. Since 2004, when Donini and his colleagues created ORTO 15, several studies have adapted this questionnaire and analyzed its psychometric characteristics in several languages. As in this case, most have had to change the initial questionnaire, eliminating one or more of the 15 original test items, and modifying the structure of the questionnaire. The final analyzes yielded a four-factor questionnaire in the analyzed sample, consisting of 14 of the 15 test items that the ORTO-15 questionnaire contains in its original version (factor 1: Obsessive cognition, test items 3, 4 and 7, factor 2: Rational cognition, test items 6, 10, 11, 12 and 14, factor 3: Emotional regulation, test items 1, 2 and 13 and factor 4: Normative Social, test items: 8, 9 and 15). This shortened version of 14 items (ORTO-14-MX) obtained a Cronbach's alpha equal to 0.78 , which is within the commonly accepted range of 
0.7 - 0.9. On the other hand, there are differences in the elimination of test items for each version. In this investigation, the test items 5 that makes reference to the question; "is flavor the main criterion when determining the quality of food" had to be eliminated. It is important to mention that these differences in the structure and design of the test with the removal of some of the test items may happen because of socio-cultural differences between different countries regarding their eating habits and customs. However, authors such as $[3,6,29]$ point out that these differences as such cannot influence the structure or design of the test. Its final reliability in terms of the detection of the pathology, given that sometimes, the elements that have been eliminated are more related to the typical symptoms of $\mathrm{ON}$, instead of some of the sociocultural factors that influence the behaviors associated with the pathology. If some of the test items that have been removed from the questionnaire are analyzed, in most of the studies carried out to date, the elimination of number 8 is significant.

Regarding the detection of the disorder, it is important to mention that people with $\mathrm{ON}$ are very inflexible with respect to their eating habits and infractions are not allowed. In this respect, the fact that this test is self-applicable and does not necessarily take place in the context of a clinical interview can make the symptoms associated with orthorexia nervosa or a predisposition to this disorder easier to detect, regardless of whether the subject recognizes the presence of this pathology or does not think he or she is committing any dietary transgression, since patients with $\mathrm{ON}$ do not consider their diet to be strict, but have simply chosen a healthy way of eating in order to improve their health, according to their criteria and beliefs. Also, in Spanish, etymologically the word "transgression" implies an intention beyond breaking the rules, but in this case, it is a selfimposed behavior and is never established by others.

Likewise, it is remarkable that item 15 (whether the subject eats alone or not), disappears in more social cultures, as is the case of the versions for Turkey and Spain, where family, work and social environment are markedly present every day at lunch time [33]. On the other hand, it is undeniable that even in more social cultures such as the Mexican, the balance between work and family also influences changing eating habits, as well as mealtimes and options. Another aspect to be highlighted is about how the different diagnostic criteria for ON could affect the design of elements in the tools for the evaluation or detection of the disease [34]. Advocates for reaching a consensus to include the criteria that derive from changes in society with relation to lifestyles. In this way, he proposes to distinguish between what he calls "enthusiasm for healthy eating", which has become generalized in contemporary society, and a higher prevalence of beliefs and eating behaviors that may lead to obsessive/compulsive behaviors. In this respect, item 1 (When you eat, do you look at the calories in the food?) highlights these differences between criteria and different versions. Did not find any statistically significant justification for maintaining this item 1 in their version [35,36], while the results of this investigation include said item, which addresses one of the most debated issues in recent times about this disorder in relation to seeing and counting calories, it can be recognized as a source of anxiety in our current society with respect to obesity and its impact on health. This should not be ignored in the detection of ON as an additional element in the obsessive rituals of these individuals. Several limitations of the study should be considered. First of all, it must be considered that the data was obtained through selfapplication and therefore, the accuracy depends on the veracity of the answers and the willingness of the participants to share experiences on this sensitive topic. Second of all, it is necessary to examine the psychometric properties of the ORTO-14-MX in other sectors of the Mexican population, since this will allow for a better degree of generalization with respect to these results.

On the other hand, it is suggested that for future studies a factor structure of the ORTO-14 MX should be confirmed, through a Confirmatory Factor Analysis (CFA) and with an independent sample of Mexican participants. Finally, this study was established in Mexico and despite having, an official body that regulates the Spanish language (Real Academia Espanola), some words of the translated version must be revised when administering the questionnaire in other Spanish-speaking countries. The availability of ORTO-14-MX will allow researchers to empirically test its psychometric properties in other Spanish-speaking countries.

Finally, it is important to have a tool for detection of $\mathrm{ON}$ at the level of clinical practice that allows professionals to identify subjects with $\mathrm{ON}$ and ED. Likewise, it is recommended that in those cases in which $\mathrm{ON}$ is detected, cognitive restructuring or demystification of false beliefs by a nutrition professional is carried out and that programs of cognitive dissonance can be offered to achieve an improvement in these subjects, both for corrective and preventive purposes. It is possible that the awareness and regulation of emotions is a protective factor for eating disorders. However, a longitudinal investigation is necessary to determine the causal direction of this relationship. Despite all the difficulties encountered in identifying orthorexia, emotional intelligence offers a way to prevent obsessive behavior by modifying personality. The desire to eat healthy foods is not a disorder in itself, but an obsession with these foods, along with the loss of moderation and balance and a withdrawal from social life caused by this eating habit, can lead to orthorexia and other foodrelated disorders.

Other studies are evaluating whether orthorexia is just a variant of the existing ways to eat and have good nutrition. However, since orthorexia involves an alteration of eating habits, it should be treated as a disorder of abnormal eating behaviors associated with obsessive symptoms (such as paying too much attention to consuming healthy foods and the quality of the food eaten). However, unlike patients affected by other eating disorders, people with orthorexia tend to respond better to treatment, precisely because of their concern for health and self-care activities. Working with the immediate environment of patients and encouraging early nutritional education are essential complements to reach the final solution to the problem. In conclusion, the values obtained in the adaptation and validation of the questionnaire for Mexican students are acceptable. The ORTO-14-MX in Spanish could be used to evaluate the scope and comorbidity of ON, as well as to design prevention programs. The questionnaire can facilitate an evaluation of the risk of orthorexia within the general population and provide fast feedback for health professionals, allowing greater control over their own practice. The use of ORTO-14 MX within a clinical context can facilitate a more complete and early assessment of a patient's risk of suffering ON. However, in the opinion of the authors, it is necessary to conduct more research to improve the instrument with new questions, useful 
for the diagnosis and evaluation of $\mathrm{ON}$.

\section{References}

1. National institute of public health. Encuesta Nacional de Salud y Nutricion de Medio Camino 2016. Informe Final de Resultados. Disponible en. 2016.

2. Gutierrez JP, Rivera-Dommarco J, Shamah-Levy T, Villalpando-Hernandez S, Franco A, Cuevas-Nasu L, et al. Encuesta Nacional de Salud y Nutricion 2012. Resultados Nacionales. Cuernavaca, Mexico: Instituto Nacional de Salud Publica (MX). 2012.

3. Missbach B, Hinterbuchinger B, Dreiseitl V, Zellhofer S, Kurz C, Konig J. When Eating Right, Is Measured Wrong! A Validation and Critical Examination of the ORTO-15 Questionnaire in German. PLoS ONE. 2015; 10: e0135772.

4. Bratman S. Health Food Junkie. Yoga Journal. 1997; 136: 42-50.

5. Cena H, Barthels F, Cuzzolaro M, Bratman S, Brytek-Matera A, Dunn T, et al Definition and diagnostic criteria for orthorexia nervosa: a narrative review of the literature. Eating and Weight Disorders: Studies on Anorexia, Bulimia and Obesity. 2019; 24: 209-246.

6. Koven NS, Abry AW. The clinical basis of orthorexia nervosa: emerging perspectives. Neuropsychiatric Disease and Treatment. 2015; 11: 385-394.

7. Volpe U, Atti AR, Cimino M, Monteleone AM, De Ronchi D, FernandezAranda F. Beyond anorexia and bulimia nervosa: What's "new" in eating disorders? Journal of Psychopathology. 2015; 21: 415-423.

8. Andreas S, Schedler K, Schulz H, Nutzinger DO. Evaluation of a German version of a brief diagnosis questionnaire of symptoms of orthorexia nervosa in patients with mental disorders (Ortho-10). Eating and weight Disorders: Studies on Anorexia, Bulimia and Obesity. 2018; 23: 75-85.

9. Arusoglu G., Kabakci E, Koksal G, Merdol TK. Orthorexia nervosa and adaptation of ORTO-11 into Turkish. Turkish journal of psychiatry. 2008; 19: 283-291.

10. Barthels F, Meyer F, Pietrowsky R. Orthorexic and restrained eating behavio in vegans, vegetarians, and individuals on a diet. Eating and weight Disorders: Studies on Anorexia, Bulimia and Obesity. 2018; 23: 159-166.

11. Brytek-Matera A, Rogoza R, Gramaglia C, Zeppegno P. Predictors of orthorexic behaviors in patients with eating disorders: a preliminary study. BMC Psychiatry. 2015; 15: 252

12. Bo S, Zoccali R, Ponzo V, Soldati L, De Carli L, Benso A, et al. University courses, eating problems and muscle dysmorphia: are there any associations? Journal Translational Medicine. 2014; 12: 221.

13. Cinosi E, Matarazzo I, Marini S, Acciavatti T, Lupi M, Corbo M, et al. Prevalence of orthorexia nervosa in a population of young Italian adults. European Psychiatry. 2015; 30: 1330

14. Depa J, Schweizer J, Bekers SK, Hilzendegen C, Stroebele-Benschop N. Prevalence and predictors of orthorexia nervosa among German students using the 21-item-DOS. Eating and Weight Disorders: Studies on Anorexia Bulimia and Obesity. 2017; 22: 193-199.

15. Saddichha S, Babu GN, Chandra P. Orthorexia nervosa presenting as prodrome of schizophrenia. Schizophrenia Research. 2012; 134: 110.

16. Kummer A, Dias FMV, Teixeira AL. On the concept of orthorexia nervosa. Scandinavian Journal of Medicine \& Science in Sports. 2008; 18: 395-396.

17. Roncero M, Barrada JR, Perpina C. Measuring Orthorexia Nervosa: Psychometric Limitations fo the ORTO-15. The Spanish Journal of Psychology. 2017; 20: e41.

18. Barthels F, Meyer F, Pietrowsky R. Orthorexic eating behavior. Ernahrungs Umschau International. 2015; 62: 156-161.

19. Dunn TM, Bratman S. On orthorexia nervosa: a review of the literature and proposed diagnostic criteria. Eating Behaviors. 2016; 21: 11-17.
20. Moroze RM, Dunn TM, Craig HJ, Yager J, Weintraub P. Microthinking about micronutrients: a case of transition from obsessions about healthy eating to near-fatal "orthorexia nervosa" and proposed diagnostic criteria. Psychosomatics. 2015; 56: 397-403.

21. Setnick J. The eating disorders clinical pocket guide, second edition: quick reference for healthcare providers. Understanding Nutrition: Dallas. 2013.

22. Dell'Osso L, Abelli M, Carpita B, Pini S, Castellini G, Carmassi C, et al. Historical evolution of the concept of anorexia nervosa and relationships with orthorexia nervosa, autism, and obsessive-compulsive spectrum. Neuropsychiatric disease and treatment. 2016; 12: 1651-1660.

23. Alvarenga M, Martins M, Sato K, Vargas S, Philipi S, Scagluisi F. Orthorexia nervosa behavior in a sample of Brazilian dietitians assessed by the Portuguese version of ORTO-15. Eating and Weight Disorders: Studies on Anorexia, Bulimia and Obesity. 2012; 17: e29- e35.

24. Ramacciotti CE, Perrone P, Coli E, Burgalassi A, Conversano C, Massimeetti $G$, et al. Orthorexia nervosa in the general population: a preliminary screening using a self-administered questionnaire (ORTO-15). Eating and Weight Disorders: Studies on Anorexia, Bulimia and Obesity. 2011; 16: e127-e130.

25. Stoche M, Janas-Kozik M, Sejda J, Hyrnik J, Jelonek I, Siwiec A. Validation of ORTO-15 Questionnaire in the group of urban youth aged 15-21. Psychiatr Pol. 2015; 49: 119-134.

26. Donini LM, Marsili D, Graziani M, Imbriale M, Cannella C. Orthorexia nervosa: Validation of a diagnosis questionnaire. Eating and weight disorders: Studies on Anorexia, Bulimia and Obesity. 2005; 10: e28-e32.

27. Donini LM, Marsili D, Graziani MP, Imbriale M, Cannella, C. Orthorexia nervosa: a preliminary study with a proposal for diagnosis and an attempt to measure the dimension of the phenomenon. Eating and Weight Disorders: Studies on Anorexia, Bulimia and Obesity. 2004; 9: 151-157.

28. Segura-Garcia C, Ramacciotti C, Rania M, Aloi M, Caroleo M, Bruni A, et al. The prevalence of orthorexia nervosa among eating disorder patients after treatment. Eating and Weight Disorders: Studies on Anorexia, Bulimia and Obesity. 2015; 20: 161-166.

29. Brytek-Matera A, Krupa M, Poggiogale E, Donini LM. Adaptation of the ORTHO-15 test to Polish women and men. Eating and Weight Disorders: Studies on Anorexia, Bulimia and Obesity. 2014; 19: 69-76.

30. Barcelos PJ, Montagner MI, Montagner MA. Orthorexia nervosa: Cultural adaptation of Ortho-15. DEMETRA: Food, Nutrition \& Health. 2014; 9: 533548.

31. Parra-Fernandez ML, Rodríguez-Cano T, Onieva-Zafra MD, Perez-Haro MJ, Casero-Alonso V, Munoz Camargo JC, et al. Adaptation and validation of the Spanish version of the ORTO-15 questionnaire for the diagnosis of orthorexia nervosa. PLOS ONE. 2018; 13: e0190722.

32. Varga M, Thege BK, Dukay-Szabo S, Tury F, van Furth EF, Bratman S, et al When eating healthy is not healthy: orthorexia nervosa and its measurement with the ORTO-15 in Hungary. BMC Psychiatry. 2014; 14: 59

33. University of Barcelona. Facultad de Psicologia and Grup d'Estudis Alimentaris de la Universitat, Anuario de Psicología. 1999; 30: 25.

34. Bratman S. Orthorexia vs. theories of healthy eating. Eating and weight Disorders: Studies on Anorexia, Bulimia and Obesity. 2017; 22: 381-385.

35. Aranceta-Bartrina J, Perez-Rodrigo C, Alberdi-Aresti G, Ramos-Carrera N, Lazaro-Masedo S. Prevalence of general obesity and abdominal obesity in the spanish adult population (aged 25-64 years) 2014-2015: The ENPE Study. Revista Espanola de Cardiología (English Edition). 2016; 69: 579-587.

36. Brytek-Matera A. Orthorexia nervosa an eating disorder, obsessivecompulsive disorder, or disturbed eating habit? Archives of Psychiatry and Psychotherapy. 2011. 